\title{
Relationship between umblical artery Doppler and perinatal outcomes in Indian women with oligohydramnios
}

\author{
Alok S. Goyal ${ }^{1}$, Saniya Goel ${ }^{1}$, Monika Gupta ${ }^{1}$, Gunvant Vaishnav ${ }^{2}$ \\ ${ }^{1}$ Department of Obstetrics \& Gynecology GMERS Medical College, Valsad, Gujarat, India \\ ${ }^{2}$ Department of Obstetrics \& Gynecology GMERS Medical College, Gotri, Vadodara, Gujarat, India
}

Received: 15 February 2016

Accepted: 11 March 2016

\author{
*Correspondence: \\ Dr. Alok S. Goyal, \\ E-mail: alokgoyaldr@gmail.com
}

Copyright: $\odot$ the author(s), publisher and licensee Medip Academy. This is an open-access article distributed under the terms of the Creative Commons Attribution Non-Commercial License, which permits unrestricted non-commercial use, distribution, and reproduction in any medium, provided the original work is properly cited.

\begin{abstract}
Background: Doppler study of umbilical artery is considered as independent predictor for perinatal adverse outcomes. Similarly oligohydramnios condition is also found to associate with perinatal mortality and morbidity. There is paucity of data regarding the relationship between abnormal Doppler of umblical artery with the perinatal outcomes in Indian subjects having oligohydramnios. Objectives of the study were, this study was done with the primary aim of evaluating any association between Doppler findings of umblical arteries with the adverse perinatal outcomes in Indian subjects having oligohydramnios.

Methods: This was an observational study in the Obstetrics and Gynecology Department of a tertiary care hospital. Women who came for antenatal checkup and having oligohydromnios were recruited in the study. Doppler of umblical artery was done and these women followed up till labour. Sociodemographic profile and other prognostic factors were noted in predesigned Performa.

Results: There were $56.1 \%$ (41 out of 73) outcomes were observed in the normal umblical artery Doppler and 51\% (14 out of 27) in abnormal umblical artery Doppler. There was no statistically significant difference in outcomes $(\mathrm{p}=0.8)$. There was no significant difference in abnormal Doppler finding between mild and severe oligohydramnios.

Conclusions: There is no relationship between abnormal Doppler findings and perinatal adverse events in oligohydramnios. Inherent methodological issues may be the reason for the same.
\end{abstract}

Keywords: Doppler, Umblical artery, Oligohydromnios, Perinatal outcomes

\section{INTRODUCTION}

The primary duty of any obstetrician is to find the high risk pregnancy at early stage so that remedial measures can be taken. One of the important risk factor is oligohydromnios i.e. reduction in amniotic fluid. This is important cause for the antenatal fetal surveillance and induction of labor. ${ }^{1}$ Incidence of oligohydromnios varies from $0.5 \%$ to $5 \%$ depend on the population studied. ${ }^{2,3}$ Oligohydramnios is considered responsible for with caesarian section, post maturity, meconium aspiration syndrome, perinatal mortality and morbidity and also found to be associated with other fetal conditions like congenital malformations, hypertension, diabetes, Intra uterine growth restriction (IUGR) etc., ${ }^{4,5}$
Umbilical artery velocimetry application in high risk pregnancies known to be associated with the favorable outcome. ${ }^{6}$ In few studies it was found that there is a correlation between perinatal mortality and morbidity and umbilical artery Doppler waveform. ${ }^{7}$ More importantly absent or reversed end diastolic umbilical artery blood flow known to be associated with high incidences of perinatal mortality, impairment of intellectual development and delay in neurodevelopmental milestones. ${ }^{8}$

Very few studies found which evaluate of association between findings of umblical artery waveform in oligohydromnios and fetal outcome. Data generated through such studies can be helpful in patient care and 
prevention of maternal and fetal mortality. So, this study was design with the primary aim of understanding the relationship between Doppler findings in oligohydramnios and perinatal mortality in Indian population.

\section{METHODS}

This study was carried out by the Department of Obstetrics and Gynaecology of a tertiary care hospital attached to medical college in South Gujarat over a period of 2 years. One hundred women who had presented to department for antenatal care after 32 weeks of gestation with oligohydromnios were enrolled.

For all the selected cases, through history was taken and complete examination was done. Clinical evidence of oligohydramnios was looked for. The previous obstetric records and ultrasound reports were reviewed. Only those women who remembered their date of last menstrual period correctly with previous regular cycles were included in the study. For all the women ultrasound examination was done and amniotic fluid index (AFI) was calculated by four quadrant amniotic fluid volume measurement technique. Oligohydramnios was defined as amniotic fluid index of less than or equal to $5 \mathrm{cms}$. Those women who were having oligohydramnios were enrolled in study and Umbilical Artery Doppler study was done in all cases. AFI was measured by the four quadrant technique originally proposed by Phelan, et al in 1987 , this method was based on the sum of total of the deepest vertical pockets in each of the four quadrants into which the uterus was divided by using the umbilicus and the linea nigra as reference points for the upper and lower halves and for the left and right halves, respectively. ${ }^{9}$ The ultrasound transducer was placed in a perpendicular plane to the patient table and in a sagittal plane to the patient herself and care was taken to see to it that it was not angled to follow the maternal abdominal curvature. Each amniotic pocket was free of fetal extremities and the umbilical cord.

Fetal biometry and morphology scan was done first, and then Doppler mode was switched on. The transducer was placed over the anterior abdominal wall, carefully manipulated till a free loop of umbilical cord seen by Grey scale imaging and colour was used to identify the umbilical artery. The Doppler waveforms were identified with the characteristic audio output and typical Doppler shift waveforms appearance on the screen, Parameters studied are S/D ratio and RI and PI in fetal umbilical artery.

For all women baseline investigations like Hemoglobin, blood group and $\mathrm{Rh}$ typing, urine examination were done. All women with oligohydramnios (AFI less than 5) were admitted and management was done. If fetal maturity was achieved (gestational age equal to or more than 36 weeks) termination of pregnancy either by induction of labour, elective or emergency cesarean section was planned according to the findings of umbilical artery Doppler study. Some patients were already in labour and were allowed to go in spontaneous labour. If fetal maturity was not achieved (gestational age between 32 and 36 weeks) and umbilical artery Doppler finding showing absent end diastolic flow or reversal of end diastolic flow, immediate termination of pregnancy was planned. If fetal maturity was not achieved and umbilical artery Doppler study shows increased umbilical artery resistance with or without centralization of flow, expectant management was planned to continue the pregnancy till maturity was achieved by -Routine management in the form of rest, left lateral position, oral and intravenous hydration and control of etiological factors was done if present. Treatment by oral or intravenous antibiotic was done, Steroidal coverage done to achieve lung maturity early, Fetal surveillance by daily fetal movement count, biweekly non stress test and amniotic fluid volume and weekly umbilical artery Doppler study was done.

Decision of delivery by either induction of labour, elective or emergency cesarean section or spontaneous labour was done as per protocol. Various outcome measures recorded on predesigned Performa like Gestational age at delivery, Mode of onset of labour and mode of delivery, Indications of cesarean delivery and incidence of emergency cesarean sections for fetal distress, Incidence of meconium staining of liquor, Fetal heart rate abnormalities during labour, Incidence of birth asphyxia, Neonatal ICU admissions, IUGR and Perinatal morbidity and mortality.

Descriptive statistics was reported in the form of frequency and percentages. The comparison of event rate was done by Fishers Exact Test. Open Epi software was used for analysis. $\mathrm{p}<0.05$ was considered as significant.

\section{RESULTS}

Almost half of the study subjects were having gestational age between 32 to 36 weeks and remaining half were having more than 36 weeks. Similarly parity (primi/multi) was also distributed almost equally. Medical risk factors were present in $33 \%$ subjects. Severe oligohyramnios was seen in 18 subjects (Table 1 ).

27 subjects were having abnormal Doppler but there was no significant association between oligohydramnios and Doppler status (Table 2). Among 51 women with oligohydramnios and between 32 and 36 weeks of gestation 45 were eligible for expectant management. In 6 subjects the pregnancy was terminated. Out of these 6 in 2 subjects there was absence of end-diastolic flow at the time of enrolment, one woman was having reversal of end diastolic flow at the time of enrollment and two women were having anhydramnios with intrauterine growth retardation and maturity was near term. One woman was having normal Doppler but with late fetal deceleration. Among 100 women with oligohydramnios 
$45 \%$ women were kept for expectant management and successfully 39 women $(86.7 \%)$ were taken to term pregnancy. Among 100 women with oligohydramnios $45 \%$ women were kept for expectant management and successfully 39 women $(86.7 \%)$ were taken to term pregnancy. Six women were having abnormal AFI but with normal Doppler study. Out of them, three women goes in spontaneous preterm labour, one was having severe oligohydramnios with normal Doppler study but having late fetal deceleration so emergency cesarean section was planned, one woman was kept on expectant management but develop severe pre-eclampsia. So, pregnancy was terminated and one woman was having severe oligohydramnios with normal Doppler with severe anemia pregnancy was terminated once baby was near term. In four women pregnancy was terminated as they were having abnormal AFI with abnormal Doppler, two women were having absent end diastolic flow in umbilical artery, one was having reversal of end diastolic flow in umbilical artery and one woman was having increased UA resistance without centralization of flow and she spontaneously went in preterm labor. In 45 women who were kept for expectant management in $35.6 \%$ of women pregnancy was prolonged for less than seven days, in $37.8 \%$ of women pregnancy was prolonged to seven to fourteen days and in $26.7 \%$ of women pregnancy was prolonged to more than fourteen days. Among 100 women 26 were taken for elective cesarean section and 74 women went in labor. In these 74 women $20.3 \%$ women were having non reassuring FHR pattern and $79.7 \%$ were having normal FHR pattern. In my study 45 women were vaginally delivered and 55 were taken for cesarean section, 26 women $(47.3 \%)$ for elective and 29 women $(52.7 \%)$ for emergency cesarean section (Table 3).

Table 1: Various prognostic parameters in study population $(n=100)$.

\begin{tabular}{|c|c|c|}
\hline Parameters & & $\begin{array}{l}\text { quency } \\
\text { rcentages) }\end{array}$ \\
\hline \multirow{2}{*}{$\begin{array}{l}\text { Gestational } \\
\text { age on first } \\
\text { examination }\end{array}$} & More than 36 weeks & $49(49)$ \\
\hline & $\begin{array}{l}\text { Between } 32 \text { and } 36 \\
\text { weeks }\end{array}$ & $51(51)$ \\
\hline \multirow{2}{*}{ Parity } & Primigravida & $48(48)$ \\
\hline & Multigravida & \\
\hline \multirow{2}{*}{$\begin{array}{l}\text { Medical Risk } \\
\text { Factors }\end{array}$} & Present & $33(33)$ \\
\hline & Absent & $67(67)$ \\
\hline \multirow{2}{*}{$\begin{array}{l}\text { Amniotic } \\
\text { Fluid Index } \\
\text { (AFI) }\end{array}$} & $\begin{array}{l}\text { Mild Oligohydramnios } \\
\text { (AFI }<5 \mathrm{cms})\end{array}$ & $82(82)$ \\
\hline & $\begin{array}{l}\text { Severe } \\
\text { Oligohydramnios } \\
(\text { AFI }<1 \mathrm{cms})\end{array}$ & $18(18)$ \\
\hline \multirow{2}{*}{ Doppler Study } & Abnormal & $27(27)$ \\
\hline & Normal & $73(73)$ \\
\hline \multirow{2}{*}{$\begin{array}{l}\text { Plan of } \\
\text { Management }\end{array}$} & Termination & $55(55)$ \\
\hline & Expectant & $45(45)$ \\
\hline \multirow{2}{*}{$\begin{array}{l}\text { Gestational } \\
\text { age at delivery }\end{array}$} & Term & $52(52)$ \\
\hline & Preterm & $10(10)$ \\
\hline
\end{tabular}

Table 2: Association between oligohydramnios severity and abnormality in doppler test.

\begin{tabular}{|c|c|c|c|c|c|}
\hline & $\begin{array}{l}\text { Normal } \\
\text { doppler }\end{array}$ & $\begin{array}{l}\text { UA } \\
\text { abnormal }\end{array}$ & $\begin{array}{l}\text { Both UA } \\
\text { and } \\
\text { MCA } \\
\text { abnormal }\end{array}$ & AEDF & REDF \\
\hline $\begin{array}{l}\text { Mild } \\
\text { oligohy- } \\
\text { dramnios } \\
(n=82)\end{array}$ & 61 & 06 & 13 & 00 & 02 \\
\hline $\begin{array}{l}\text { Severe } \\
\text { oligohy- } \\
\text { dramnios } \\
(n=18)\end{array}$ & 12 & 00 & 04 & 02 & 00 \\
\hline
\end{tabular}

Table 3: Various parameters related to the management and prognosis in the study subjects.

\begin{tabular}{|c|c|c|}
\hline Parameters & \multicolumn{2}{|c|}{ Frequency (\%) } \\
\hline \multirow{3}{*}{$\begin{array}{l}\text { Indication for } \\
\text { Interventions } \\
(n=100)\end{array}$} & Maturity achieved & $90(90)$ \\
\hline & Abnormal AFI alone & $06(6)$ \\
\hline & $\begin{array}{l}\text { Abnormal AFI with } \\
\text { Abnormal Doppler }\end{array}$ & $04(4)$ \\
\hline \multirow{3}{*}{$\begin{array}{l}\text { Duration of } \\
\text { prolongation of } \\
\text { pregnancy }(n=45)\end{array}$} & Less than 7 days & $16(35.6)$ \\
\hline & $\begin{array}{l}\text { Between } 7 \text { and } 14 \\
\text { days }\end{array}$ & $17(37.8)$ \\
\hline & More than 14 days & $12(26.7)$ \\
\hline \multirow[t]{2}{*}{$\begin{array}{l}\text { FHR pattern } \\
\text { during labour } \\
(\mathrm{n}=74)\end{array}$} & Normal & $59(79.7)$ \\
\hline & Abnormal & $15(20.3)$ \\
\hline \multirow{3}{*}{$\begin{array}{l}\text { Mode of delivery } \\
(\mathrm{n}=100)\end{array}$} & Vaginal & $45(45)$ \\
\hline & Elective LSCS & $26(26)$ \\
\hline & Emergency LSCS & $29(29)$ \\
\hline \multirow[t]{2}{*}{$\begin{array}{l}\text { Neonatal } \\
\text { Outcome }(n=100)\end{array}$} & $\begin{array}{l}\text { Normal (term, } \\
\text { normal APGAR, no } \\
\text { NICU Admission, no } \\
\text { mortality, no MAS }\end{array}$ & $69(69)$ \\
\hline & Abnormal & $31(31)$ \\
\hline
\end{tabular}

There was a significant difference $(\mathrm{p}=0.87)$ in normal Doppler and abnormal Doppler for adverse prognostic criteria like cesarean section, fetal distress, non-progress of labour etc (Table 4).

Table 4: Comparison of adverse prognostic parameters between normal and abnormal Doppler subjects.

\begin{tabular}{|lll|}
\hline Indications & $\begin{array}{l}\text { Normal Doppler } \\
(\mathbf{n = 7 3})\end{array}$ & $\begin{array}{l}\text { Abnormal } \\
\text { Doppler }(\mathbf{n}=27)\end{array}$ \\
\hline $\begin{array}{l}\text { Elective } \\
\text { Cesarean }\end{array}$ & $20(27.4)$ & $06(22.2)$ \\
\hline Fetal Distress & $12(16.4)$ & $07(25.9)$ \\
\hline $\begin{array}{l}\text { Liquor Thick } \\
\text { Meconium }\end{array}$ & $06(8.2)$ & 00 \\
\hline $\begin{array}{l}\text { Non Progress } \\
\text { of Labour }\end{array}$ & $03(4.1)$ & $01(3.7)$ \\
\hline
\end{tabular}




\section{DISCUSSION}

This study was designed with the aim of understanding the relationship between Doppler study of fetal umblical artery in oligohydramnios and pregnancy outcome.

There are several studies which found that in the case of oligohydramnios there can be normal Doppler findings in the case of umbilical arteries and in such cases there is significantly less risk of perinatal mortality as compared to the cases having abnormal umblical artery Doppler findings. ${ }^{10}$ In the study by Carroll BC, 81 cases of known oligohydramnios were recruited and Doppler study was done. It was observed that in the subjects with normal Doppler $37 \%$ were having perinatal adverse outcomes while in the subjects with abnormal Doppler $80 \%$ has adverse pregnancy outcomes. ${ }^{[10]}$ There are many other studies which have similar findings. ${ }^{[11]}$ In present study there was no significant difference between group having abnormal umblical artery Doppler and group having normal umblical artery Doppler for perinatal outcome. There were $56.1 \%$ (41 out of 73) outcomes were observed in the normal umblical artery Doppler and 51\% (14 out of 27) in abnormal umblical artery Doppler. Opposite finding in our study may be because of the methodological reasons like purposive sampling and less number of subjects in abnormal umblical artery Doppler group or it may be because of the characteristics of subjects recruited in the study.

In this study there was no significant difference mild and severe oligahyramnios for abnormal Doppler findings. Several other studies published also have similar findings that Doppler findings are independent predictors for the perinatal outcomes similarly oligahyramnios is also an independent predictor for perinatal mortality. There may be no relationship between oligahyramnios and abnormal Doppler. $^{12,13}$

In present study, the adverse pregnancy outcomes were not significantly different in the oligohydramnios with abnormal Doppler findings as compared to the oligohydramnios with normal Doppler. So, there is no association of abnormal fetal umblical artery Doppler with the perinatal outcomes but there is need of studies with rigorous methodological quality and adequate sample size to reach to the logical conclusion.

The major limitation of this study is sampling. The sample was not drawn randomly and sample size was small hence the negative findings of this study may be because of less sample size.

\section{CONCLUSIONS}

There is no relationship between abnormal Doppler findings and perinatal adverse events in oligohydramnios. Inherent methodological issues may be the reason for the same.
Funding: No funding sources

Conflict of interest: None declared

Ethical approval: The study was approved by the Institutional Ethics Committee

\section{REFERENCES}

1. Zhang J, Troendle J, Meikle S, Klebanoff MA, Rayburn WF. Isolated oligohydramnios is not associated with adverse perinatal outcomes. BJOG: An International Journal of Obstetrics \& Gynaecology. 2004;111(3):220-5.

2. Hill LM, Breckle R, Wolfgram KR, O'Brien PC. Oligohydramnios: ultrasonically detected incidence and subsequent fetal outcome. American journal of obstetrics and gynecology. 1983;147(4):407-10.

3. Mercer LJ, Brown LG, Petres RE, Messer RH. A survey of pregnancies complicated by decreased amniotic fluid. American journal of obstetrics and gynecology. 1984;149(3):355-61.

4. Casey BM, McIntire DD, Bloom SL, Lucas MJ, Santos R, Twickler DM. Pregnancy outcomes after antepartum diagnosis of oligohydramnios at or beyond 34 weeks' gestation. American journal of obstetrics and gynecology. 2000;182(4):909-12.

5. McCurdy CM, Seeds JW. Oligohydramnios: problems and treatment. Seminars in perinatology. 1993;17(3):183-96.

6. Neilson JP, Alfirevic Z. Doppler ultrasound for fetal assessment in high risk pregnancies. The Cochrane database of systematic reviews. 2000;(2):CD000073.

7. Soregaroli M, Bonera R, Danti L, Dinolfo D, Taddei F, Valcamonico A. Prognostic role of umbilical artery Doppler velocimetry in growth-restricted fetuses. The journal of maternal-fetal \& neonatal medicine : the official journal of the European Association of Perinatal Medicine, the Federation of Asia and Oceania Perinatal Societies, the International Society of Perinatal Obstet. 2002;11(3):199-203.

8. Wienerroither H, Steiner H, Tomaselli J, Lobendanz M, Thun-Hohenstein L. Intrauterine blood flow and long-term intellectual, neurologic, and social development. Obstetrics and gynecology. 2001;97(3):449-53.

9. Phelan JP, Smith CV, Broussard P, Small M. Amniotic fluid volume assessment with the fourquadrant technique at 36-42 weeks' gestation. J Reprod Med. 1987;32(7):540-2.

10. Carroll BC, Bruner JP. Umbilical artery Doppler velocimetry in pregnancies complicated by oligohydramnios. The Journal of reproductive medicine. 2000;45(7):562-6.

11. Kwon JY, Kwon HS, Kim YH, Park YW. Abnormal Doppler velocimetry is related to adverse perinatal outcome for borderline amniotic fluid index during third trimester. The journal of obstetrics and gynaecology research. 2006;32(6):545-9.

12. Yoon BH, Lee CM, Kim SW. An abnormal umbilical artery waveform: a strong and independent 
predictor of adverse perinatal outcome in patients with preeclampsia. American journal of obstetrics and gynecology. 1994;171(3):713-21.

13. Locatelli A, Vergani P, Toso L, Verderio M, Pezzullo JC, Ghidini A. Perinatal outcome associated with oligohydramnios in uncomplicated term pregnancies. Archives of gynecology and obstetrics. 2004;269(2):130-3.
Cite this article as: Goyal AS, Goel S, Gupta M, Vaishnav G. Relationship between umblical artery Doppler and perinatal outcomes in Indian women with oligohydramnios. Int J Reprod Contracept Obstet Gynecol 2016;5:1187-91. 